\title{
A glycoprotein from Porphyra yezoensis produces anti-inflammatory effects in liposaccharide-stimulated macrophages via the TLR4 signaling pathway
}

\author{
EUN-SOON SHIN*, HYE-JUNG HWANG* ${ }^{*}$ IN-HYE KIM and TAEK-JEONG NAM
}

Faculty of Food Science and Biotechnology, Pukyong National University, Nam-gu, Busan 608-737, Republic of Korea

Received April 28, 2011; Accepted June 2, 2011

DOI: 10.3892/ijmm.2011.729

\begin{abstract}
The purpose of this study was to investigate the antioxidant and anti-inflammatory effects of a glycoprotein isolated from the alga Porphyra yezoensis in LPS-stimulated RAW 264.7 mouse macrophages. First, we extracted a novel material with antioxidant activity from $P$. yezoensis, confirmed by SDS-PAGE to be a glycoprotein, which we named $P$. yezoensis glycoprotein (PGP). PGP inhibited the production of NO and ROS and expression of iNOS, COX-2, TNF- $\alpha$ and IL-1 $\beta$, which are involved in the pathogenesis of many inflammation-associated human diseases, including septic shock, hemorrhagic shock and rheumatoid arthritis. Next, we determined the mechanisms behind the antioxidant and antiinflammatory activities of PGP. We focused on the Toll-like receptor 4 (TLR4) signaling pathway because it is well-known to induce the pro-inflammatory proteins that trigger MAPK and $\mathrm{NF}-\kappa \mathrm{B}$ activation in lipopolysaccharide (LPS)-induced oxidative events. PGP treatment reduced the formation of the TLR4-IRAK4 and TLR4-TRIF binding complexes in response to LPS. Moreover, it inhibited LPS-induced activation and nuclear translocation of NF- $\kappa$ B by abrogating I $\kappa$ B phosphorylation. PGP also suppressed the phosphorylation of ERK1/2 and JNK in a dose-dependent manner. These results suggest that PGP exerts its anti-inflammatory effects by modulating TLR4 signaling and thus inhibiting the activation of NF- $\kappa \mathrm{B}$ and MAP kinases.
\end{abstract}

\section{Introduction}

Antioxidants have become the subject of intensive investigation due to the ever-increasing demand by the food and pharmaceutical industries to develop natural, bioactive

Correspondence to: Dr Taek-Jeong Nam, Faculty of Food Science and Biotechnology, Pukyong National University, 599-1 Daeyeon 3-Dong, Nam-gu, Busan 608-737, Republic of Korea

E-mail: namtj@pknu.ac.kr

*Contributed equally

Key words: Toll-like receptor 4, glycoprotein, imflammation antiaging, and anticarcinogenic compounds that produce measurable health benefits. Many of the synthetic antioxidants developed, however, produce side effects such as liver damage and carcinogenesis (1). Due to concerns regarding the toxicity of synthetic antioxidants, the search for alternatives from natural sources has received a great deal of interest. Recently, studies have focused on marine algae as a potential source of such activities because they have been shown to contain many biologically active compounds with potential medicinal value, and their consumption has been associated with a reduced risk of several chronic diseases. Moreover, many bioactive molecules from marine algae produce antioxidant effects. For example, the antioxidant activity of sulfated polysaccharides from seaweed has been investigated $(2,3)$. Phloroglucinol purified from Conyza aegyptiaca was shown to protect cells from oxidative damage by increasing cellular catalase activity and by regulating the extracellular signal-related kinase (ERK) signaling pathway (4). It was also shown to inhibit the production of nitrite, a known precursor of carcinogenic N-nitroso compounds $(5,6)$. Elsewhere, 5-hydroxymethyl-2-furfural isolated from marine red algae demonstrated antioxidant activities such as free-radical scavenging and myeloperoxidase (MPO) inhibition, and increased the expression of superoxide dismutase (SOD) and glutathione (GSH) (7). Meanwhile, fucoidan and other polysaccharide-rich extracts have shown good superoxide anion scavenging ability $(8,9)$. In addition, an antioxidant substance purified from the red seaweed Gloiopeltis tenax demonstrated antioxidant activity in a 1,1-diphenyl-2-picrylhydrazyl (DPPH) assay (10).

Most of these studies on algal extracts have simply investigated antioxidant effects such as free-radical scavenging, nitric oxide (NO) scavenging, and SOD production. Such antioxidant activities are useful in controlling chronic systemic inflammation. We thus examined how algal extracts regulate inflammatory responses induced by oxidative stress. We focused on the Toll-like receptor 4 (TLR4) signaling pathway, which is centrally involved in the inflammatory effects of lipopolysaccharide (LPS) and which regulates the nuclear factor (NF) $-\kappa B$ and mitogen-activated protein kinase (MAPK) signaling pathways.

Binding of LPS to TLR4 is important in the initiation and propagation of inflammatory responses $(11,12)$. It results in the activation of two signaling pathways: MyD88-dependent 
and -independent. In the MyD88-dependent pathway, MyD88 recruits interleukin (IL)-1 receptor-associated kinase 4 (IRAK4) to TLR4 and thereby facilitates IRAK4-mediated phosphorylation of IRAK1. Phosphorylated IRAK1 subsequently dissociates from the receptor complex and associates with tumor necrosis factor (TNF) receptor-associated factor 6 (TRAF6) (13-15). TLR4-mediated production of inflammatory cytokines, which is believed to be primarily induced via the MyD88-dependent pathway, was shown to be defective in Toll/IL-1 receptor (TIR) domain-containing adaptor protein inducing interferon (IFN)- $\beta$ (TRIF) and TRIF-related adaptor molecule (TRAM) knockout mice (16). This strongly suggests that TRIF is involved in TLR4-mediated induction of inflammatory cytokine production. TLR4 binds to TRAM, which in turn recruits TRIF (17). TRIF binds to TRAF6 directly, resulting in IRAK1/4-independent activation of transforming growth factor (TGF)- $\beta$-activated kinase 1 (TAK1) $(18,19)$. TRIF also binds to receptor (TNFRSF)-interacting serine-threonine kinase 1 (RIP1), which itself binds to TRAF6, ultimately resulting in activation of the I- $\mathrm{kB}$ kinase (IKK) complex (20).

In the present study, we extracted a glycoprotein (PGP) from $P$. yezoensis that has antioxidant and anti-inflammatory effects, and assessed the potential contribution of TLR4 signaling to the anti-inflammatory mechanism of PGP.

\section{Materials and methods}

PGP preparation. P. yezoensis, purchased at the Myonggi traditional market, Busan, Korea, in February 2009, was desalted by washing and then dried using a freeze-dryer. A crude aqueous extract was prepared by mixing the resulting $P$. yezoensis powder with distilled water and incubating the resulting mixture at room temperature for $3 \mathrm{~h}$. The aqueous extract was clarified by centrifugation and filtered to remove insoluble materials. The filtrate was mixed with three volumes of ethanol and then condensed before ammonium sulfate was added to a final concentration of $80 \%$. The resulting solution was dialyzed against distilled water and then concentrated. The product obtained was stored at $-20^{\circ} \mathrm{C}$ prior to use.

We next analyzed our sample (containing $0.1 \%$ SDS; $100 \mu \mathrm{g} /$ lane) by SDS-PAGE using a $17 \%$ polyacrylamide mini-gel and a Mini-Protean II electrophoresis cell (Bio-Rad, Hercules, CA, USA). Protein separation was performed at $110 \mathrm{~V}, 30 \mathrm{~mA}$ for $2 \mathrm{~h}$. The glycoprotein was identified by staining with Schiff's reagent, which specifically detects glycoproteins as a result of a redox reaction. The final amount of PGP obtained from $160 \mathrm{~g}$ of dried powder was $14.704 \mathrm{~g}$ (yield 9.19\%).

Cell culture. Mouse RAW 264.7 cells (ATCC CRL-1592) were obtained from the American Type Culture Collection (Rockville, MD, USA). The cells were cultured in Dulbecco's modified Eagle's medium (DMEM) supplemented with 10\% fetal bovine serum (FBS) (Hyclone, Logan, UT, USA) and antibiotics. Cultures were maintained in a humidified incubator at $37^{\circ} \mathrm{C}$ in $5 \% \mathrm{CO} 2$ and the medium was replaced every 2 days.

Cell proliferation assay. The effects of PGP treatment on cell proliferation were colorimetrically determined in a MTS assay performed using the CellTiter 96 AQueous One Solution reagent (Promega, Madison, WI, USA). Cells were seeded in 96-well plates at a density of $1.5 \times 10^{5}$ cells/well. After $24 \mathrm{~h}$, the medium was exchanged for DMEM supplemented with $0.02 \%$ FBS. Twelve hours later, this medium was replaced with fresh DMEM containing $0.02 \%$ FEB and PGP $(1-5 \mu \mathrm{g} / \mathrm{ml})$. The cells were incubated for an additional $24 \mathrm{~h}$.

Cells were exposed to an MTS assay solution for $30 \mathrm{~min}$ at $37^{\circ} \mathrm{C}$ and optical densities at $490 \mathrm{~nm}$ were measured using a microplate reader (Bio-Rad). The $\mathrm{OD}_{490}$ values of untreated cells were assigned a value of $100 \%$.

Nitrite assay. Culture medium nitrite concentrations were measured as an indicator of NO production according to the Griess reaction. Briefly, $100 \mu \mathrm{l}$ of each supernatant was mixed with the same volume of Griess reagent ( $1 \%$ sulfanilamide, $0.1 \%$ naphthylethylenediamine dihydrochloride in $5 \%$ aqueous phosphoric acid). Absorbances of the resulting mixtures at $550 \mathrm{~nm}$ were measured using a microplate reader (Bio-Rad).

ROS assay. Intracellular reactive oxygen species (ROS) accumulation was quantified using DCF-DA reagent (Sigma-Aldrich, St. Louis, MO, USA). Cells were treated for $24 \mathrm{~h}$ with LPS $(100 \mathrm{ng} / \mathrm{ml})$, alone or in combination with PGP $(1-5 \mu \mathrm{g} / \mathrm{ml})$, and further incubated with DCF-DA $(10 \mu \mathrm{M})$ for $20 \mathrm{~min}$. Cells were washed twice with ice-cold phosphate-buffered saline (PBS) and intracellular levels of ROS were analyzed using a fluorescence microplate reader (excitation, $485 \mathrm{~nm}$; emission, $535 \mathrm{~nm}$ ).

Western blot analysis. Protein samples $(50 \mu \mathrm{g})$ loaded onto 7.5-12.5\% gradient gels were separated by SDS-PAGE and transferred to polyvinylidene fluoride (PVDF) membranes (Millipore, Billerica, MA, USA). Membranes were blocked with $1 \%$ bovine serum albumin (BSA) in TBS-T [10 mM Tris- $\mathrm{HCl}$ (pH 7.5), $150 \mathrm{mM} \mathrm{NaCl}, 0.1 \%$ Tween-20], and then incubated with the indicated antibodies (diluted 1:1,000 in TBS-T containing 1\% BSA) with gentle shaking overnight at $4^{\circ} \mathrm{C}$. They were then incubated with a peroxidase-conjugated goat anti-mouse or anti-rabbit secondary antibody (diluted 1:10,000). Signals were detected using an ECL Western blotting kit (Amersham, Piscataway, NJ, USA).

Immunoprecipitation. RAW 264.7 cells were treated with LPS $(100 \mathrm{ng} / \mathrm{ml})$, alone or in combination with PGP $(1-5 \mu \mathrm{g} / \mathrm{ml})$ for $24 \mathrm{~h}$, and then washed in cold PBS. Proteins were isolated using cold lysis buffer $[10 \mathrm{mM}$ Tris- $\mathrm{HCl}(\mathrm{pH} 7.4), 150 \mathrm{mM} \mathrm{NaCl}$, $1 \%$ Nonidet P-40] containing protease inhibitors $(1 \mu \mathrm{g} / \mathrm{ml}$ aprotinin, $1 \mathrm{mM} \mathrm{NaF}, 1 \mathrm{mM} \mathrm{NaVO}{ }_{3} 1 \mu \mathrm{g} / \mathrm{ml}$ leupeptin, $1 \mathrm{mM}$ PMSF). Lysed cell samples were centrifuged at $15,000 \mathrm{~g}$ for $15 \mathrm{~min}$. The resulting supernatants were incubated overnight at $4^{\circ} \mathrm{C}$ with the appropriate antibodies. Immune complexes were subsequently captured by incubation for $2 \mathrm{~h}$ at $4^{\circ} \mathrm{C}$ with protein $\mathrm{G}$ agarose (Sigma-Aldrich). The beads were successively washed with cold lysis buffer and sample buffer. Finally, samples were boiled at $100^{\circ} \mathrm{C}$. Eluted proteins were loaded onto 7.5-12.5\% gradient gels, separated by SDS-PAGE, and transferred to PVDF membranes (Millipore). Membranes were blocked with $1 \%$ BSA in TBS-T and then incubated with the indicated antibodies (diluted 1:1,000 in TBS-T containing $1 \%$ BSA) with gentle shaking overnight at $4^{\circ} \mathrm{C}$. Secondary antibody treatments and signal detection were performed as described above. 


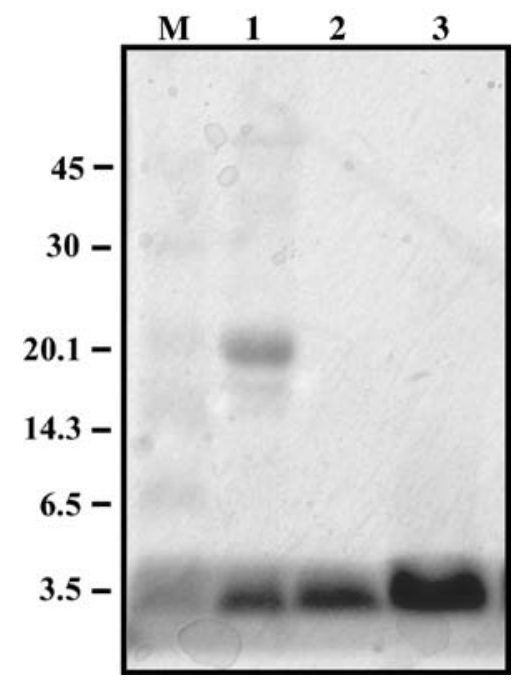

Figure 1. SDS-PAGE profile of PGP. The extract from P. yezoensis was separated by SDS-PAGE and then stained for glycoproteins. The extraction process involved several sequential steps. $M$, marker; 1 , water extract; 2 , ethanol extract; 3 , the product.

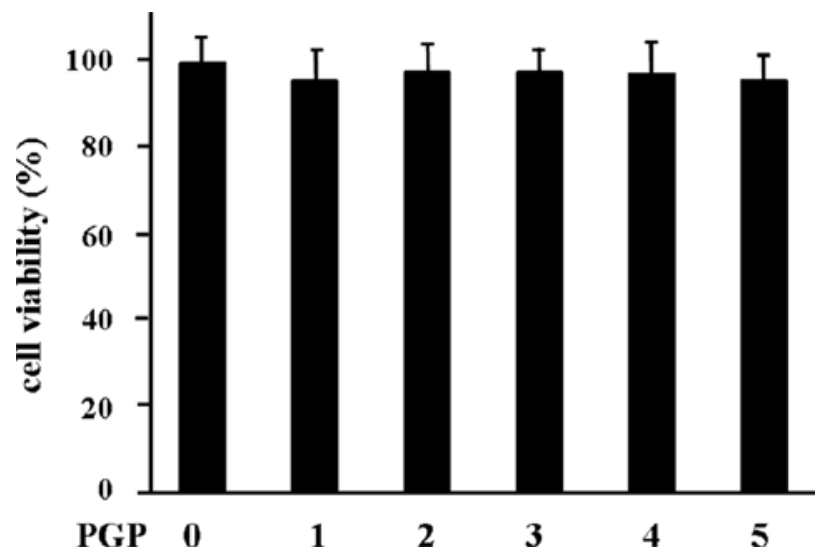

Figure 2. Effect of PGP on the proliferation of RAW 264.7 macrophages. RAW 264.7 cells were incubated with the indicated concentrations of PGP Cell viability was determined by an MTS assay. Data are presented as the mean \pm SD. Values from treated and control cells did not differ significantly [Duncan's multiple range test $(\mathrm{P}<0.05)]$.

A

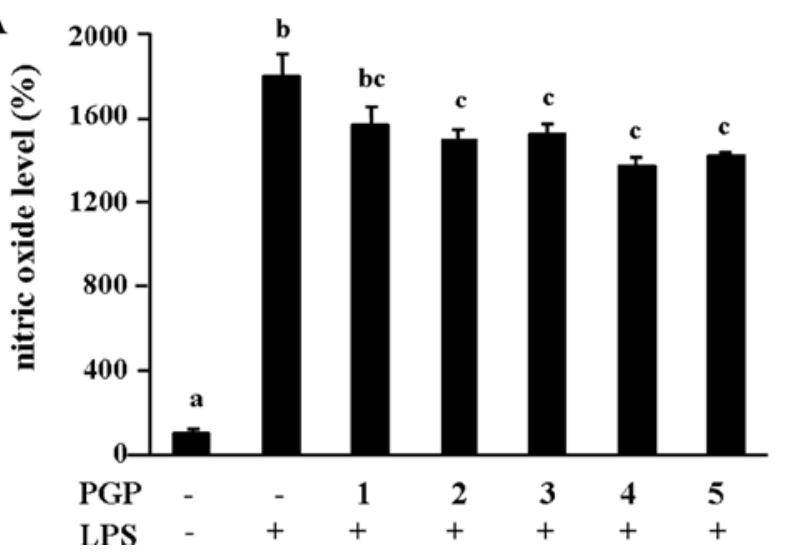

Statistical analysis. All samples were analyzed in triplicate. Data are presented as the mean \pm SD. SPSS (SPSS Inc., Chicago, IL, USA) was used to test statistical significance by analysis of variance (ANOVA). A value of $\mathrm{P}<0.05$ was considered to be statistically significant.

\section{Results}

Antioxidant effect of PGP. Through a combination of SDS-PAGE and glycoprotein staining, we identified our extract of $P$. yezoensis as being a glycoprotein of about $3.5 \mathrm{kDa}$ (Fig. 1), which we named PGP. We next examined whether PGP could affect the proliferation of RAW 264.7 cells and confirmed that, at the concentrations examined $(1-5 \mu \mathrm{g} / \mathrm{ml})$, it had no significant effect on cell proliferation (Fig. 2). We therefore concluded that PGP (at a concentration of $1-5 \mu \mathrm{g} / \mathrm{ml}$ ) had no cytotoxic effects on RAW 264.7 cells and could be used in further studies.

To investigate PGP's potential antioxidant properties, we assessed its effects on the levels of oxidative stress in RAW 264.7 cells treated with LPS $(100 \mathrm{ng} / \mathrm{ml})$. PGP reduced the LPS-induced production of NO and ROS in RAW 264.7 cells. In the case of NO, LPS increased its production $1,790.6 \pm 108.7 \%$. Co-administration of PGP dose-dependently reduced NO production (Fig. 3A). PGP similarly inhibited LPS-induced intracellular ROS production (LPS itself increased ROS production by $231.5 \pm 8.2 \%$ ) (Fig. 3B). The ability of PGP to reduce NO production may limit the inflammatory response to LPS.

Anti-inflammatory effect of PGP. Because cytokine levels are indicators of the progression of inflammation, we measured the effects of PGP treatment on levels of oxide synthase (iNOS), cyclooxygenase (COX)-2, IL- $1 \beta$ and TNF- $\alpha$ in LPS-treated macrophages (Fig. 4). PGP suppressed the induction of all four proteins by LPS (LPS itself increased iNOS, COX-2, IL-1 $\beta$ and TNF- $\alpha$ levels by $310.3 \pm 37.7,270.0 \pm 41.5,207.3 \pm 27.8$ and $199.2 \pm 29.7 \%$, respectively). These effects on inflammatory cytokines were more pronounced than the suppressive effect of PGP on NO and ROS production. Therefore, suppression of these mediators may be an effective strategy for preventing inflammatory reactions

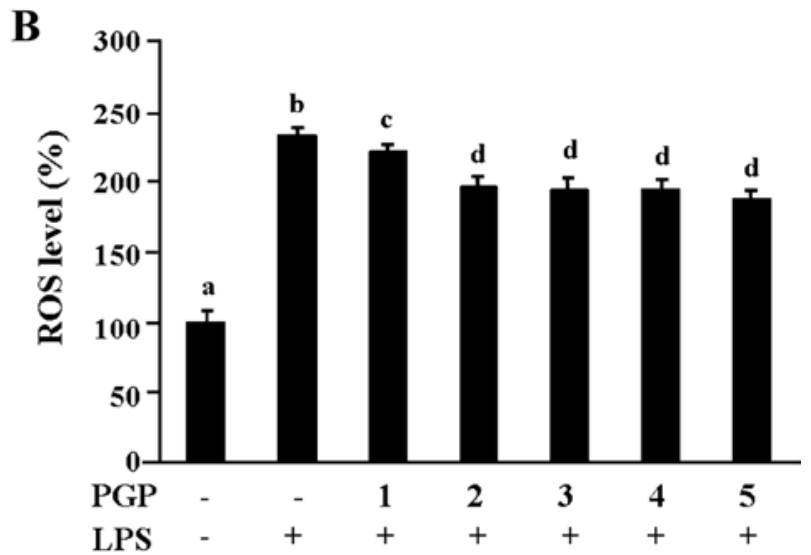

Figure 3. Effect of PGP on the production of NO and ROS by LPS-activated RAW 264.7 macrophages. Cells were incubated with 100 ng/ml LPS, alone or in combination with different concentrations of PGP, for $24 \mathrm{~h}$. (A) NO production; (B) ROS production. Data are presented as the mean \pm SEM of tests performed in triplicate. c,d Statistically significant difference compared to the LPS-treated group $(\mathrm{P}<0.05)$. 

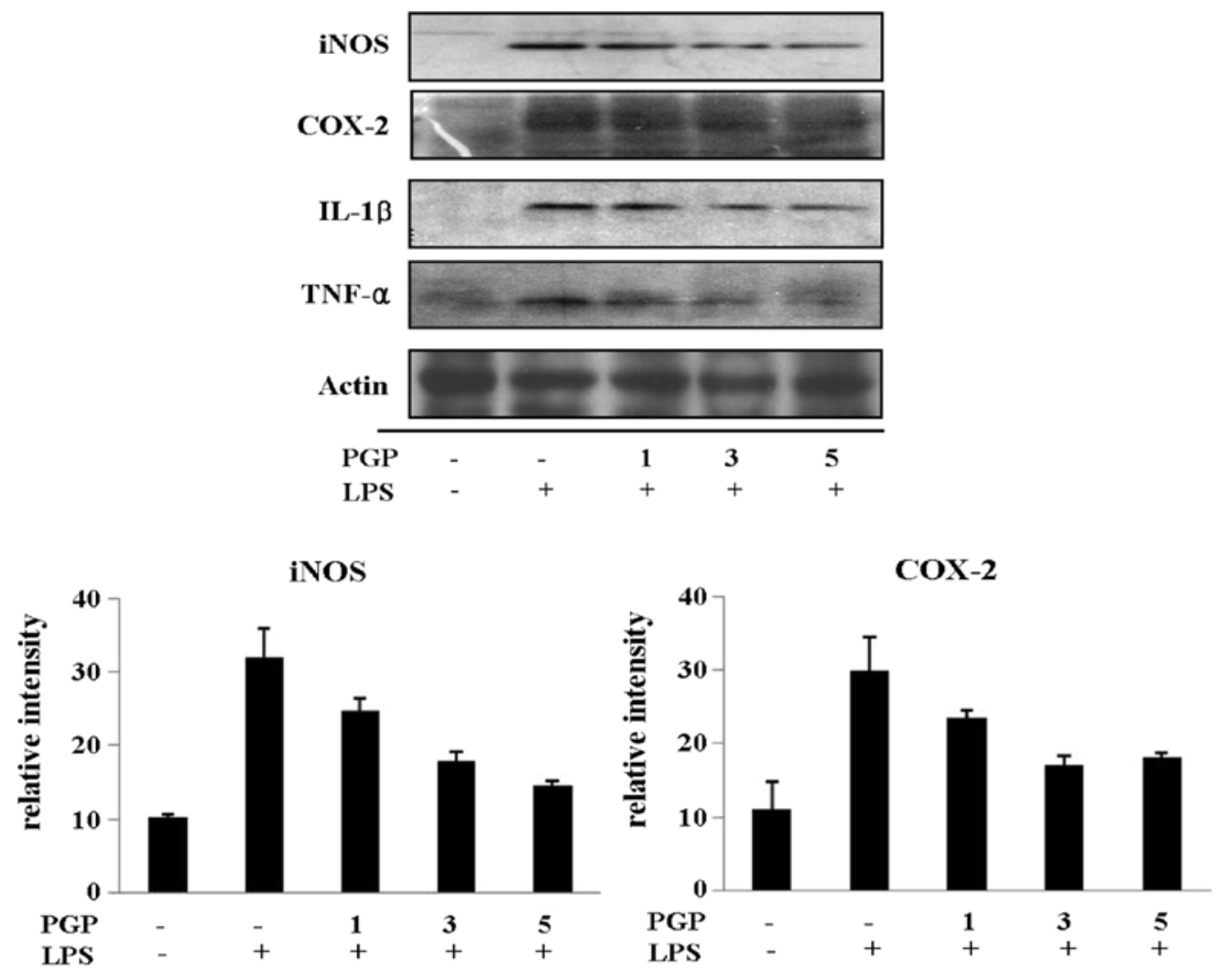

\section{IL-1 $\beta$}
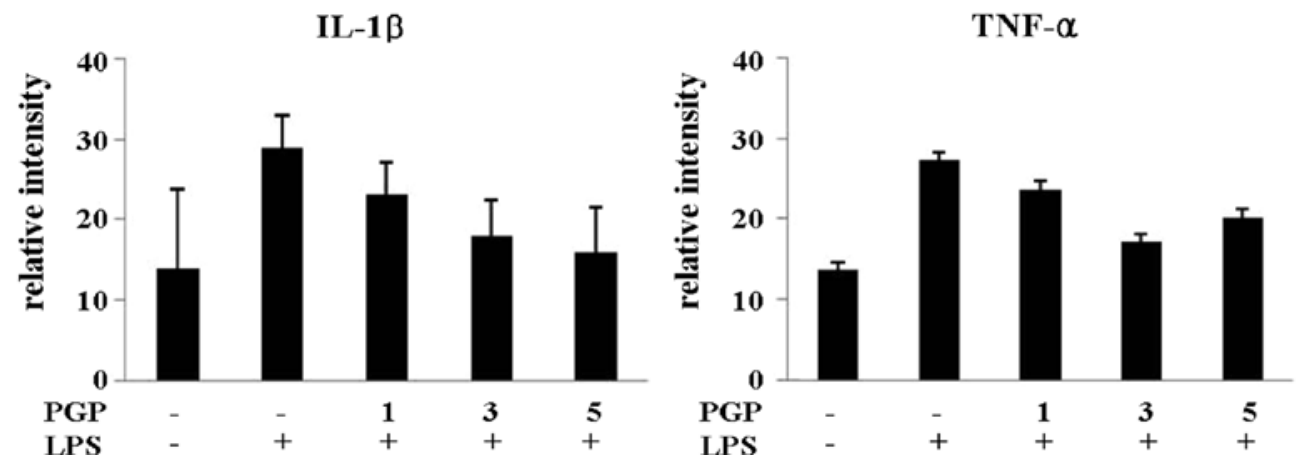

Figure 4. Effect of PGP on the levels of pro-inflammatory mediators and cytokines in LPS-activated RAW 264.7 macrophages. RAW 264.7 cells were treated with LPS, alone or in combination with different concentrations of PGP, for $24 \mathrm{~h}$, and lysed. Protein samples were analyzed by Western blotting using the following antibodies at the indicated concentrations: anti-iNOS $(1: 1,000)$, anti-COX-2 $(1: 1,000)$, anti-IL-1 $(1: 1,000)$ and anti-TNF- $\alpha(1: 1,000)$.

Effect of PGP on TLR-4 signaling. PGP did not affect the expression of TLR4 or MyD88 in LPS-treated macrophages (Fig. 5A). However, it suppressed LPS-induced TRAF6 production and recruitment of IRAK4 to TLR4. These data suggest that PGP regulates the MyD88-dependent pathway, which controls downstream activation of NF- $\mathrm{KB}$ and MAPK. Thus, we conclude that PGP controls the binding of IRAK4 to TLR4 in LPS-activated cells, thereby reducing levels of TRAF6 (Fig. 5B).

Effect of PGP on NF- $\kappa B$ signaling. Our finding that co-treatment with PGP and LPS blocked the nuclear translocation of NF- $\kappa \mathrm{B}$ by inhibiting its activation suggested that suppression of pro-inflammatory mediators may result from the attenuation of NF- $\mathrm{NB}$ activation. We thus investigated whether PGP could prevent the phosphorylation of I $\mathrm{K} \mathrm{B} \alpha$. We found that
PGP reduced LPS-induced IкB $\alpha$ phosphorylation in a dosedependent manner (Fig. 6A).

To investigate whether NF- $\mathrm{kB}$ is an important target for the anti-inflammatory action of PGP in macrophages, we examined the effects of PGP on NF- $\mathrm{KB}$ activation in cells treated with LPS. The results showed that PGP blocks the activation and nuclear translocation of NF- $\kappa \mathrm{B}$ by interfering with LPS-induced phosphorylation of I $\mathrm{KB} \alpha$ (Fig. 6B). Taken together, these results suggest that PGP inhibits LPS-induced nuclear translocation and activation of NF- $\mathrm{KB}$ by attenuating the phosphorylation of I $\mathrm{B} \alpha$.

Effect of PGP on MAPK signaling. Because MAPK signaling plays a critical role in the responses of cells to various cytokines and stresses, we investigated the effects of PGP on the MAPK pathways. LPS increased the phosphorylation of p38, ERK1/2, 


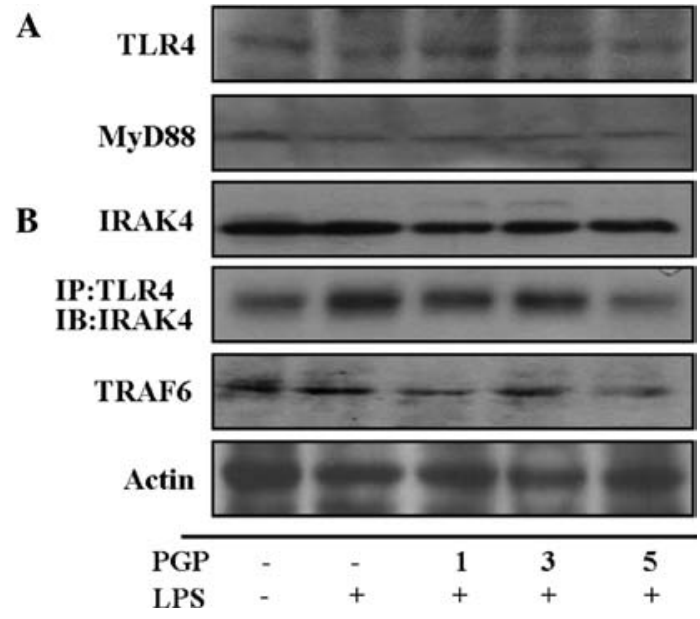

Figure 5. Effect of PGP on TLR4 signaling in LPS-activated RAW 264.7 macrophages. RAW 264.7 cells were treated with LPS, alone or in combination with different concentrations of PGP, for $24 \mathrm{~h}$, and lysed. Protein samples were analyzed by Western blotting or immunoprecipitation using the indicated antibodies. (A) MyD88-dependent pathway; (B) MyD88independent pathway.

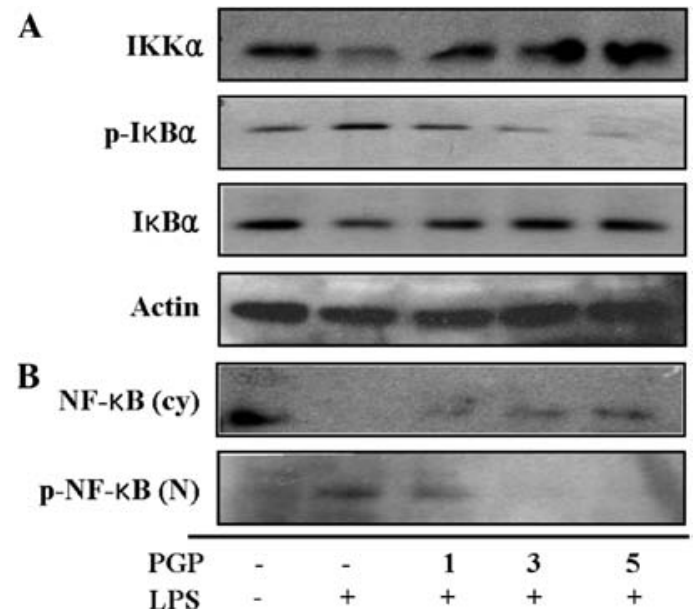

Figure 6. Effect of PGP on NF- $\mathrm{KB}$ signaling in LPS-activated RAW 264.7 macrophages. RAW 264.7 cells were treated with LPS, alone or in combination with different concentrations of PGP, for $24 \mathrm{~h}$. (A) Cytosolic lysates were prepared and analyzed by Western blotting using the following antibodies at the indicated concentrations: anti-IKK $\alpha(1: 1,000)$, anti-IкB $\alpha(1: 1,000)$, and anti-phospho-IкB $\alpha(1: 1,000)$. (B) Cytosolic and nuclear extracts were prepared and analyzed by Western blotting using the following antibodies at the indicated concentrations: anti-NF- $\mathrm{kB}(1: 1,000)$ and anti-phospho-NF- $\mathrm{KB}$ (1:500).

and Jun N-terminal kinase (JNK) by $160 \pm 6.9,163 \pm 1.2$ and $122.4 \pm 16.8 \%$, respectively. PGP reduced the phosphorylation of ERK1/2 and JNK, but not that of p38, in LPS-treated cells (Fig. 7). These results suggest that suppression of ERK and JNK phosphorylation may contribute to the inhibitory effect of PGP on LPS-stimulated expression of inflammatory mediators in RAW 264.7 cells.

\section{Discussion}

While marine algae have recently been shown to contain several biologically active compounds with medicinal effects, the consumption of algae is associated with a reduced risk

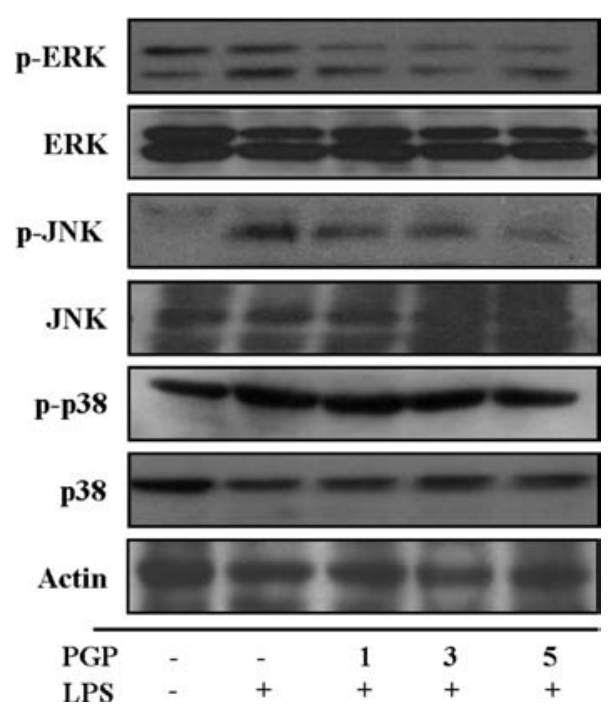

Figure 7. Effect of PGP on MAPK signaling in LPS-activated RAW 264.7 macrophages. RAW 264.7 cells were treated with LPS, alone or in combination with different concentrations of PGP, for $24 \mathrm{~h}$, and lysed. Protein samples were analyzed by Western blotting using the following antibodies at the indicated concentrations: anti-ERK (1:1000), anti-phospho-ERK $(1: 1,000)$, anti-JNK $(1: 1,000)$, anti-phospho-JNK $(1: 1,000)$, anti-p38 $(1: 1,000)$ and anti-phospho-p38 (1:500).

of developing several chronic diseases. Notable among the many bioactive effects of marine algae are their antioxidant effects. For example, 5-hydroxymethyl-2-furfural isolated from marine red algae demonstrated various antioxidant activities, including free-radical scavenging, MPO inhibition, and induction of SOD and GSH expression (7). Elsewhere, polysaccharide-rich extracts including fucoidan have shown strong superoxide anion scavenging ability $(3,8,9)$. In addition, a substance with antioxidant properties purified from the red seaweed Gloiopeltis tenax displayed antioxidant activity in a DPPH assay (10). In this study, we extracted a bioactive glycoprotein with antioxidant properties from the red algae P. yezoensis (Figs. 1 and 2) and named it PGP.

To further explore PGP's antioxidant effects, we evaluated its ability to protect RAW 264.7 macrophages from LPS-induced oxidative stress. Treatment with PGP reduced the production of NO and ROS in LPS-exposed RAW 264.7 cells (Fig. 3). A signaling molecule that plays a key role in the development of inflammation, NO is overproduced under abnormal physiological conditions (21-23). Therefore, the ability of PGP to reduce NO production may limit the inflammatory response to LPS. In addition, because ROS act as important second messengers that regulate NF- $\mathrm{\kappa B}$-dependent gene expression, their reduced production and/or enhanced clearance in PGP-treated cells may limit the ability of LPS to activate NF- $\mathrm{KB}$ and induce the transcription of genes encoding inflammatory mediators (24-27). Thus, PGP may effectively inhibit inflammation by reducing intracellular ROS generation.

We subsequently confirmed PGP's ability to reduce inflammation. When applied to RAW 264.7 cells, it attenuated LPS-induced expression of pro-inflammatory mediators and cytokines including inducible iNOS, COX-2, TNF- $\alpha$ and IL-1 $\beta$ (Fig. 4). Expression of iNOS, COX-2, IL- $1 \beta$ and TNF- $\alpha$ requires the activation of $\mathrm{NF}-\kappa \mathrm{B}$, an important proximal 
mediator of the overproduction of inflammatory mediators in macrophages exposed to LPS and cytokines that plays critical roles in apoptosis, autoimmunity, and inflammation $(28,29)$. Production of large amounts of NO by iNOS has been proposed to cause cell injury through the generation of reactive radicals such as peroxynitrite. It also causes the nitrosylation of several proteins, including some that are involved in cell signaling (30). During inflammatory processes, macrophages secrete TNF- $\alpha$ and other cytokines including IL-1 $\beta$ and IL-12 to combat injury (31). Uncontrolled feedback inhibition of cytokine production may result in disease. Under inflammatory conditions, for example, in rheumatoid arthritis, homeostatic control of apoptosis/proliferation may be lost due to a cytokine imbalance (32). TNF- $\alpha$ and IL-1 $\beta$ are key pro-inflammatory cytokines in various immune cells, including macrophages, monocytes, and $\mathrm{T}$ cells, which have various pro-inflammatory effects in chronic inflammatory diseases (33). Therefore, the suppression of these mediators should be an effective strategy for preventing inflammatory reactions.

TLR4 is a key component of the innate immune system and functions as a pattern recognition receptor for LPS, a potent immunostimulatory glycolipid and constituent of the outer membrane of gram-negative bacteria (34). After its activation by LPS, TLR4 in turn activates an inflammatory cascade in macrophages that involves the activation of MAPKs and nuclear translocation of NF- $\mathrm{NB}$ (35), a transcription factor controlling the expression of a range of cytokines and pro-inflammatory mediators $(36,37)$. TLR4 activates both MyD88-dependent and MyD88-independent signaling pathways and induces the production of both pro-inflammatory cytokines, including IFN- $\gamma$ (16). Activation of the MyD88-dependent pathway involves the sequential recruitment of the adaptor molecule MyD88, IRAK family proteins and TRAF6 $(38,39)$. TRAF6 subsequently triggers the activation of MAP kinases and, as a result of TAK-1-mediated IKK activation, NF- $\mathrm{B}$ (40).

First, we examined whether PGP regulates MyD88dependent TLR4 signaling, a key effector of the response to LPS (41). PGP did not influence the expression of TLR4 or MyD88 in LPS-treated macrophages (Fig. 5A). However, it suppressed LPS-induced TRAF6 expression and recruitment of IRAK4 to TLR4. These data suggest that PGP regulates the MyD88dependent pathway, which controls the downstream activation of NF- $\kappa \mathrm{B}$ and MAPK.

Recent studies revealed that LPS activates both NF- $\kappa \mathrm{B}$ and MAPK in cells from MyD88-knockout mice (42-44), implying the existence of an alternative signaling pathway. We thus investigated whether PGP was able to modulate this so-called 'MyD88-independent' signaling pathway. PGP inhibited the recruitment of IRAK4 to TLR4 in LPS-activated cells (Fig. 5B). Thus, we conclude that PGP controls the binding of IRAK4 to TLR4 in LPS-activated cells, thereby reducing levels of TRAF6.

Known to play critical roles in the regulation of cell survival, NF- $\kappa \mathrm{B}$ controls the expression of enzymes and cytokines with roles in inflammation, including iNOS, COX-2, TNF- $\alpha$ and IL-1 $\beta(45,46)$. Our finding that PGP blocked the nuclear translocation of NF- $\kappa \mathrm{B}$ in LPS-treated cells by inhibiting its activation suggests that the observed suppression of pro-inflammatory mediators may result from the attenuation of $\mathrm{NF}-\kappa \mathrm{B}$ activation.
Antioxidants such as curcumin and ascorbic acid have been reported to inactivate $\mathrm{NF}-\kappa \mathrm{B}$ by inhibiting the phosphorylation of $\mathrm{I} \kappa \mathrm{B} \alpha(47,48)$. We thus investigated whether PGP could prevent $\mathrm{I} \kappa \mathrm{B} \alpha$ phosphorylation. We found that PGP reduced LPS-induced phosphorylation of $\mathrm{I} \kappa \mathrm{B} \alpha$ in a dose-dependent manner (Fig. 6A).

MAP kinases regulate various inflammatory and immune responses, including LPS-induced expression of COX-2 and iNOS in macrophages (49). The inhibition of MAPK family members, including ERK, p38, and JNK, blocks the production of pro-inflammatory cytokines (50). Because MAPK signaling plays a critical role in the responses of cells to various cytokines or stresses, we investigated the effects of PGP on MAPK signaling in RAW 264.7 macrophages. Treatment with PGP attenuated LPS-mediated activation ERK and JNK, but not p38 (Fig. 7). These findings suggest that suppression of the phosphoactivation of ERK and JNK may contribute to the inhibitory effects of PGP on the LPS-stimulated expression of inflammatory mediators in RAW 264.7 cells.

In conclusion, PGS attenuated the expression of the inflammatory mediators, iNOS, COX-2, IL- $1 \beta$ and TNF- $\alpha$ in LPS-activated macrophages. LPS-induced formation of TLR4-IRAK4 complexes was suppressed by PGP in a MyD88dependent manner. In addition, $P$ GP reduced the binding of TRIF to TLR4 in a MyD88-independent manner. These results show that PGP inhibits the ability of LPS to activate TLR4 signaling pathways, both MyD88-dependent and MyD88-independent, and thereby limits the activation of MAPK and NF- $\mathrm{BB}$.

\section{Acknowledgements}

This study was undertaken as part of a larger project titled 'Development for Novel Biofunctional Protein Source from Marine Algae Produced in the Coastal Area of Busan' and funded by the Ministry of Land, Transport and Maritime Affairs, Korea.

\section{References}

1. Tezuka Y, Irikawa T, Kaneko AH, Banskota T, Nagaoka Q Xiong K, Hase R and Kadota S: Screening of Chinese herbal drug extracts for inhibitory activity on nitric oxide production and identification of an active compound of Zanthoxylum bungeanum. J Ethnopharmacol 77: 209-217, 2001.

2. Ye H, Wang KQ, Zhou CH, Liu J and Zeng XX: Purification, anti-tumor and antioxidant activities in vitro of polysaccharides from the brown seaweed Sargassum pallidum. Food Chem 111: 428-443, 2008.

3. Costa LS, Fidelis GP, Cordeiro SL, Oliveira RM, Sabry DA, Câmara RBG, Nobre LT, Costa MS, Almeida-Lima J, Farias EH, Leite EL and Rocha HA: Biological activities of sulfated polysaccharides from tropical seaweeds. Biomed Pharmacother 64: 21-28, 2010.

4. Kang KA, Lee KH, Chae SW, Zhang R, Jung MS, Ham YM, Baik JS, Lee NH and Hyun JW: Cytoprotective effect of phloroglucinol on oxidative stress induced cell damage via catalase activation. J Cell Biochem 97: 609-620, 2006.

5. Choi JS, Lee JH and Jung JH: The screening of nitrite scavenging effect of marine algae and active principle of Ecklonia stolonifera. J Korean Fish Soc 30: 909-915, 1997.

6. Park YB: Determination of nitrite-scavenging activity of seaweed. J Korean Soc Food Sci Nutr 34: 1293-1296, 2005.

7. Li YX, Li Y, Qian ZJ, Kim MM and Kim SK: In vitro antioxidant activity of 5-HMF isolated from marine red alga Laurencia undulata in free-radical-mediated oxidative systems. J Microbiol Biotechnol 19: 1319-1327, 2009.

8. Qi H, Zhang Q, Zhao T, Chen R, Zhang H, Niu X and Li Z: Antioxidant activity of different sulfate content derivatives of polysaccharide extracted from Ulva pertusa (Chlorophyta) in vitro. Int J Biol Macromol 37: 195-199, 2005. 
9. Xing RG, Liu S, Yu HH, Guo ZY, Li Z and Li PC: Preparation of high-molecular weight and high-sulfate content chitosans and their potential antioxidant activity in vitro. Carbohydr Pol 61: 148-154, 2005.

10. Lim BL and Ryu IH: Purification, structural characterization, and antioxidant activity of antioxidant substance from the red seaweed Gloiopeltis tenax. J Med Food 12: 442-451, 2009.

11. Hallenbeck JM: The many faces of tumor necrosis factor in stroke. Nat Med 8: 1363-1368, 2002.

12. Janeway CA Jr and Medzhitov R: Innate immune recognition. Annu Rev Immunol 20: 197-216, 2002.

13. Cao Z, Xiong J, Takeuchi M, Kurama T and Goeddel DV: TRAF6 is a signal transducer for interleukin-1. Nature 383: 443-446, 1996

14. Li S, Strelow A, Fontana EJ and Wesche H: IRAK-4: a nove member of the IRAK family with the properties of an IRAKkinase. Proc Natl Acad Sci USA 99: 5567-5572, 2002.

15. Suzuki N, Suzuki S, Duncan GS, Millar DG, Wada T, Mirtsos C, Takada H, Wakeham A, Itie A, Li S, Penninger JM, Wesche H, Ohashi PS, Mak TW and Yeh WC: Severe impairment of interleukin-1 and Toll-like receptor signalling in mice lacking IRAK-4 Nature 416: 750-756, 2002.

16. Yamamoto M, Sato S, Hemmi H, Uematsu S, Hoshino K, Kaisho T, Takeuchi O, Takeda K and Akira S: TRAM is specifically involved in the Toll-like receptor 4-mediated MyD88-independent signaling pathway. Nat Immunol 4: 1144-1150, 2003.

17. Fitzgerald KA, Rowe DC, Barnes BJ, Caffrey DR, Visintin A Latz E, Monks B, Pitha PM and Golenbock DT: LPS-TLR4 signaling to IRF-3/7 and NF-KB involves the Toll adapters TRAM and TRIF. J Exp Med 198: 1043-1055, 2003.

18. Jiang Z, Zamanian-Daryoush M, Nie H, Silva AM, Williams BR and Li X: Poly(I-C)-induced Toll-like receptor 3 (TLR3)mediated activation of NFkappaB and MAP kinase is through an interleukin-1 receptor-associated kinase (IRAK)-independent pathway employing the signaling components TLR3-TRAF6TAK1-TAB2-PKR. J Biol Chem 278: 16713-16719, 2003.

19. Jiang Z, Mak TW, Sen G and Li X: Toll-like receptor 3-mediated activation of NF-kappaB and IRF3 diverges at Toll-IL-1 receptor domain-containing adapter inducing IFN-beta. Proc Natl Acad Sci USA 101: 3533-3538, 2004.

20. Meylan E, Burns K, Hofmann K, Blancheteau V, Martinon F, Kelliher M and Tschopp J: RIP1 is an essential mediator of Toll-like receptor 3-induced NF-kappaB activation. Nat Immunol 5: 503-507, 2004.

21. McCartney-Francis N, Allen JB, Mizel DE, Albina JE, Xie QW, Nathan CF and Wahl SM: Suppression of arthritis by an inhibitor of nitric oxide synthase. J Exp Med 178: 749-754, 1993.

22. Lin MW, Tsao LT, Huang LJ, Kuo SC, Weng JR, Ko HH, Lin CN, Lee MR and Wang JP: Inhibition of lipopolysaccharidestimulated NO production by crotafuran B in RAW 264.7 macrophages involves the blockade of NF-kappaB activation through the increase in IkappaBalpha synthesis. Toxicol App Pharmacol 210: 108-115, 2006

23. Sharma JN, Al-Omran A and Parvathy SS: Role of nitric oxide in inflammatory diseases. Inflammopharmacology 6: 252-259, 2007.

24. Han YJ, Kwon YG, Chung HT, Lee SK, Simmons RL, Billiar TR and Kim YM: Antioxidant enzymes suppress nitric oxide production through the inhibition of NF-kappaB activation: role of $\mathrm{H}_{2} \mathrm{O}_{2}$ and nitric oxide in inducible nitric oxide synthase expression in macrophages. Nitric Oxide 5: 504-513, 2001.

25. Lee SJ, Bai SK, Lee KS, Namkoong S, Na HJ, Ha KS, Han JA, Yim SV, Chang K, Kwon YG, Lee SK and Kim YM: Astaxanthin inhibits nitric oxide production and inflammatory gene expression by suppressing IkappaB kinase-dependent NF-kappaB activation. Mol Cells 16: 97-105, 2003.

26. Asehnoune K, Strassheim D, Mitra S, Kim JY and Abraham E: Involvement of reactive oxygen species in Toll-like receptor 4-dependent activation of NF-kappaB. J Immunol 172: 2522-2529, 2004

27. Gloire G, Legrand-Poels S and Piette J: NF-kappaB activation by reactive oxygen species: fifteen years later. Biochem Pharmaco 72: 1493-1505, 2006.

28. Shapira L, Soskolne WA, Houri Y, Barak V,Halabi A and Stabholz A Protection against endotoxic shock and lipopolysaccharide-induced local inflammation by tetracycline: correlation with inhibition of cytokine secretion. Infect Immun 64: 825-828, 1996.

29. Yamamoto Y and Gaynor RB: Therapeutic potential of inhibition of the NF-kappaB pathway in the treatment of inflammation and cancer. J Clin Invest 107: 135-142, 2001

30. Kuncewicz T, Sheta EA, Goldknopf IL and Kone BC: Proteomic analysis of S-nitrosylated proteins in mesangial cells. Mol Cell Proteomics 2: 156-163,2003.
31. Weinstein SL, Gold MR and DeFranco AL: Bacterial lipopolysaccharide stimulates protein tyrosine phosphorylation in macrophages. Proc Natl Acad Sci USA 15: 4148-4152, 1991.

32. Mountz JD, Hsu HC, Matsuki Y and Zhang HG: Apoptosis and rheumatoid arthritis: past, present, and future directions. Curr Rheumatol Rep 3: 70-78, 2001.

33. Andreakos E, Foxwell B and Feldmann M: Is targeting Toll-like receptors and their signaling pathway a useful therapeutic approach to modulating cytokine-driven inflammation? Immunol Rev 202: 250-265, 2004

34. Doyle SL and O'Neill LA: Toll-like receptors: from the discovery of NFkappaB to new insights into transcriptional regulations in innate immunity. Biochem Pharmacol 72: 1102-1113, 2006.

35. O'Neill LA: Signal transduction pathways activated by the IL-1 receptor/toll-like receptor superfamily. Curr Top Microbiol Immunol 270: 47-61, 2002.

36. Chen V, Castranova V and Shi X: New insights into the role of nuclear factor- $\kappa \mathrm{B}$ in cell growth regulation. Am J Pathol 159: 387-397, 2001

37. Bours V, Bonizzi G, Bentires-Alj M, Bureau F, Piette J, Lekeux P and Merville M: NF- $\mathrm{BB}$ activation in response to toxical and therapeutical agents: role in inflammation and cancer treatment. Toxicology 153: 27-38, 2000

38. Kopp EB and Medzitov R: The Toll-receptor family and control of innate immunity. Curr Opin Immunol 11: 13-18, 1999.

39. Dziarski R and Gupta D: Role of MD-2 in TLR2- and TLR4mediated recognition of Gram-negative and Gram-positive bacteria and activation of chemokine genes. J Endotoxin Res 6 : 401-405, 2000

40. Noman AS, Koide N, Hassan F, I-E-Khuda I, Dagvadorj J, Tumurkhuu G, Islam S, Naiki Y, Yoshida T and Yokochi T: Thalidomide inhibits lipopolysaccharide-induced tumor necrosis factor-alpha production via down-regulation of MyD88 expression. Innate Immun 15: 33-41, 2009.

41. O'Neill LA and Bowie AG: The family of five: TIR-domaincontaining adaptors in Toll-like receptor signaling. Nat Rev Immunol 7: 353-364, 2007.

42. Kawai T, Adachi O, Ogawa T, Takeda K and Akira S: Unresponsiveness of MyD88-deficient mice to endotoxin. Immunity 11: 115-122, 1999.

43. Lomaga MA, Yeh WC, Sarosi I, Duncan GS, Furlonger C, Ho A Morony S, Capparelli C, Van G, Kaufman S, van der Heiden A, Itie A, Wakeham A, Khoo W, Sasaki T, Cao Z, Penninger JM, Paige CJ, Lacey DL, Dunstan CR, Boyle WJ, Goeddel DV and Mak TW: TRAF6 deficiency results in osteopetrosis and defective interleukin-1, CD40, and LPS signaling. Genes Dev 13: 1015-1024, 1999

44. Swantek JL, Tsen MF, Cobb MH and Thomas JA: IL-1 receptorassociated kinase modulates host responsiveness to endotoxin. J Immunol 164: 4301-4306, 2000.

45. Baeuerle PA and Baltimore D: NF-kappa B: ten years after. Cell 87: 13-20, 1996.

46. Kim JB, Han AR, Park EY, Kim JY, Cho W, Lee J, Seo EK and Lee KT: Inhibition of LPS-induced iNOS, COX-2 and cytokines expression by Poncirin through the NF-kappaB inactivation in RAW 264.7 macrophage cells. Biol Pharm Bull 30: 2345-2351, 2007.

47. Shishodia S, Potdar P, Gairola CG and Aggarwal BB: Curcumin (diferuloylmethane) down-regulates cigarette smoke-induced NF-kappaB activation through inhibition of IkappaBalpha kinase in human lung epithelial cells: correlation with suppression of COX-2, MMP-9 and cyclin D1. Carcinogenesis 24: 1269-1279, 2003

48. Carcamo JM, Pedraza A, Borquez-Ojeda O, Zhang B, Sanchez R and Gold DW: Vitamin $C$ is a kinase inhibitor: dehydroascorbic acid inhibits IkappaBalpha kinase beta. Mol Cell Biol 24: 6645-6652, 2004.

49. Ajizian SJ, English BK and Meals EA: Specific inhibitors of p38 and extracellular signal-regulated kinase mitogen-activated protein kinase pathway block inducible nitric oxide synthase and tumor necrosis factor accumulation in murine macrophages stimulated with lipopolysaccharide and interferon-gamma. J Infect Dis 179: 939-944, 1999.

50. Sironi L, Banfi C, Brioschi M, Gelosa P, Guerrini U, Nobili E, Gianella A, Paoletti R, Tremoli E and Cimino M: Activation of NF-kappaB and ERK1/2 after permanent focal ischemia is abolished by simvastatin treatment. Neurobiol Dis 22: 445-451, 2006. 